\title{
Effect of Additional Instrumentation with the Xp-Endo Finisher versus the Self-Adjusting File on the Push-Out Bond Strength of Different Sealers
}

\author{
Emre Bayram ${ }^{1 *}$, Hüda Melike Bayram ${ }^{1}$, Mine Büker², Meltem Sümbüllü̈ ${ }^{2}$, Esra Kul ${ }^{3}$ and Ertuğrul Karataş ${ }^{2}$ \\ ${ }^{1}$ Department of Endodontics, Gaziosmanpaşa University, Turkey \\ ${ }^{2}$ Department of Endodontics, Atatürk University, Turkey \\ ${ }^{3}$ Department of Prostodontics, Atatürk University, Turkey \\ Received: January 05, 2018; Published: January 17, 2018 \\ *Corresponding author: Emre Bayram, Department of Endodontics, Faculty of Dentistry, Gaziosmapasa University, Tokat, 60200, Turkey, \\ Email: bayremre@yahoo.com
}

Abstract

Objectives: To compare the push-out bond strength of root fillings made with either 2 Seal or TotalFill BC sealer after the additional instrumentation of oval canals with either the XP-endo Finisher (XP) or Self Adjusting File (SAF) systems.

Material and Methods: Mandibular premolars with single oval canal were collected for the study. Root canals were prepared with Reciproc R25 and were randomly divided into six groups $(\mathrm{n}=10)$, as follows: group 1, additional instrumentation with SAF and filling using 2Seal and gutta-percha (GP); group 2, additional instrumentation with SAF and filling using Total Fill BC and GP; group 3, additional instrumentation with XP and filling using 2Seal and gutta-percha; group 4, additional instrumentation with XP and filling using TotalFill BC and GP; group 5, canal filling with 2seal and GP without additional instrumentation; group 6, canal filling with Total Fill BC and GP without additional instrumentation. Each sample was sectioned horizontally into $1 \mathrm{~mm}$ thick slices at each thirds and push-out test was performed using universal testing machine. Three-way ANOVA and Tukey's post-hoc tests were performed to compare groups.

Results: The bond strength values of the XP group were significantly higher than the values of the SAF and Reciproc groups $(\mathrm{P}<0.05)$. There was no statistically significant difference among the groups regarding the failure types.

Conclusion: Additional instrumentation applications of the XP for teeth with complex canal anatomy, such as oval-shaped canals, might increase the bond strength of different types of sealers

Keywords: Endodontics; XP-endo Finisher; Self-Adjusting File; Push-out bond strength; Root canal sealer

Abbreviations: SAF: Self Adjusting File System; WL: Working Length

\section{Introduction}

One of the most important stages of root canal treatment is the chemo-mechanical preparation of the root canal system and decontamination to prevent bacteria [1]. However, some unclean areas have been reported during chemo-mechanical preparation, especially of oval-shaped canals [2]. It has been found that more than $40 \%$ of the canal walls of this kind of complex root structure are not properly cleaned [2-4]. A new file system known as the XP-Endo Finisher (XP) (FKG Dentaire, La Chaux-de-Fonds, and Switzerland) has been recently introduced. The file is straight in its M-phase, which is achieved when it is cooled. When the file is exposed to the body temperature of the canal, it changes its shape according to the molecular memory of the A-phase (Figure 1). According to the manufacturer, XP allows mechanical cleaning of the canal in areas previously impossible to reach due to its phase transformation. $\mathrm{XP}$ is recommended to be used as a finishing file system. The Selfadjusting File System (SAF) (ReDent Nova, Ra'anana, and Israel) uses a hollow file in root canal preparation to circumferentially remove a layer of dentin in oval and round canals [5].

One previous study reported that the SAF system minimizes the untouched area within the oval canal by protecting the canal anatomy while providing better preparation [6]. 2Seal (VDW, Endodontic Synergy, Munich, Germany) is a root canal sealer that contains a newly developed epoxy resin [7]. TotalFill BC sealer (FKG Dentaire, La-Chaux-de-Fonds, Switzerland) is a highly 
antimicrobial, biocompatible, and osteo-inductive calcium silicatebased root canal sealer that is not affected by dentin moisture $[8,9]$. Previous studies have reported that if the buccal and lingual areas of the canal are clean, the strength of the bond between the root filling material and the root canal walls increases [10]. To the best of our knowledge, no studies have evaluated the effect of the XP file system on the bond strength of root canal sealers. Therefore, the present study was designed to compare the push-out bond strength of root fillings made with either 2Seal or TotalFill BC sealer after the additional instrumentation of oval canals with either the XP or SAF system. The null hypothesis is that the push-out bond strength is not affected by file system or sealer type.

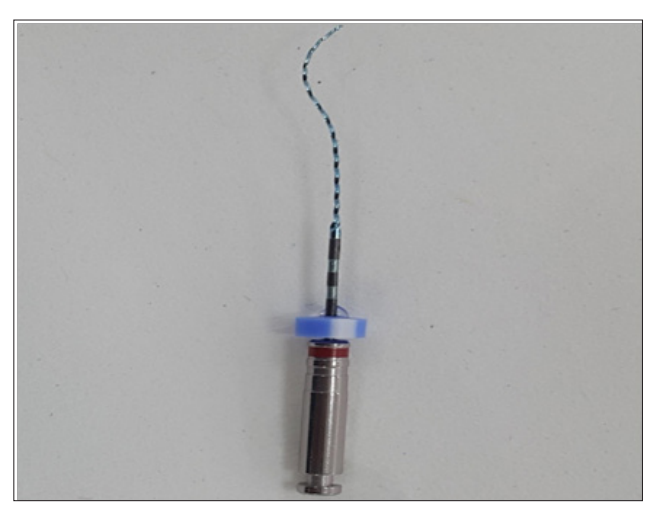

Figure 1: The Austenitic phase shape of the XP file $\left(35^{\circ} \mathrm{C}\right)$ (FKG Dentaire, La Chaux-de-Fonds, Switzerland).

\section{Materials and Methods}

\section{Selection of Teeth}

Mandibular premolars with a single root and a single canal were collected for this study. Buccolingual and mesiodistal radiographs of all teeth were taken in order to identify oval canals and to confirm the presence of a single canal without previous root canal treatment, resorptions, or calcifications. Teeth with buccolingual dimensions 2.5 times larger than the mesiodistal dimensions at $5 \mathrm{~mm}$ from the apex were included [11]. In accordance with this, 60 teeth with oval-shaped canals were selected. Next, the crowns of the teeth were cut at the cement enamel junction to remain 15 $\mathrm{mm}$ in length. A size $10 \mathrm{~K}$-file (Mani Inc. Tochigi, Japan) was placed in all teeth until just visible at the apex to determine patency. The working length (WL) of the canals was determined. Root canals were prepared with Reciproc R25 (VDW, Munich, Germany) files using a VDW Silver Reciproc motor (VDW) and the "Reciproc All" program. The root canals were irrigated with $5 \mathrm{ml}$ of $5.25 \% \mathrm{NaOCl}$ solution during instrumentation. After instrumentation, all the samples were randomly divided into six groups $(n=10)$, as follows:

a)Group 1: Additional instrumentation with SAF followed by filling of the root canals using 2Seal and gutta-percha

b)Group 2: Additional instrumentation with SAF followed by filling of the root canals using TotalFill BC and gutta-percha

c)Group 3: Additional instrumentation with XP followed by filling of the root canals using 2 Seal and gutta-percha
d)Group 4: Additional instrumentation with XP followed by filling of the root canals using TotalFill BC and gutta-percha

e)Group 5: Canal filling with 2seal and gutta-percha without additional preparation

f)Group 6: Canal filling with Total Fill BC and gutta-percha without additional preparation

\section{Additional Instrumentation}

Groups 1 and 2: In accordance with Metzger et al. [12], a 1.5 mm SAF instrument was attached to a special head (RDT3, ReDent Nova) that allows in-and-out vibrations at 5,000 vibrations/min and $0.4 \mathrm{~mm}$ descending speed. The file system was attached to a Vatea peristaltic pump (ReDent Nova), a special irrigation device, and irrigation was carried out at the same time as the preparation. Instrumentation was carried out for $4 \mathrm{~min}$ with $5.25 \% \mathrm{NaOCl}$ irrigation solution in order to reach the WL of the canals.

Groups 3 and 4: An XP file was used for additional instrumentation. In order to provide XP's phase transformation, root canals were filled with $5.25 \% \mathrm{NaOCl}$ solution heated to $37{ }^{\circ} \mathrm{C}$. In total, $16 \mathrm{ml}$ of $\mathrm{NaOCl}$ was used, and the solution was renewed continuously. The file was used at $1000 \mathrm{rpm}$ and $1 \mathrm{~N} \mathrm{~cm}$ torque for $1 \mathrm{~min}$ for each canal, according to the manufacturer's recommendations.

Groups 5 and 6: No additional preparation was used. Additional irrigation was achieved using $16 \mathrm{ml}$ of $5.25 \% \mathrm{NaOCl}$.

In order to remove the smear layer within the root canals, the canals were irrigated with $5 \mathrm{ml}$ of $17 \%$ EDTA and $5 \mathrm{ml}$ of $5.25 \%$ $\mathrm{NaOCl}$ solution for $1 \mathrm{~min}$ each. Next, in order to remove the effects of the irrigation solution and any debris present in the root canals, $5 \mathrm{ml}$ of distilled water was used. The root canals were dried with paper cones (Spident, NamDong KongDon, Inchon, Korea).

\section{Root Canal Filling}

For groups 1, 3, and 5, 2 Seal canal sealer was used. While being present in form of two tubes, 2Seal is prepared by mixing as equal quantities. For groups 2,4 , and 6 , TotalFill BC, which is a ready-to-use injection preparation (Brasseler USA, Savanah, GA, USA), was used according to the manufacturer's recommendations. The canal wall was coated with root canal sealer using a lentulo spiral. The master cone was placed, and cold lateral compaction was performed using a size $25 \mathrm{NiTi}$ finger spreader (Dentsply Tulsa Dental, Tulsa, OK, USA) and accessory cones. Excess gutta-percha was cut using a heated hand plugger. Samples were controlled with mesiodistal and buccolingual radiographs to confirm complete root canal filling. Access cavities were sealed with temporary filling material (Cavit G, 3M ESPE, Seefeld, Germany) and the teeth were left in $100 \%$ humidity for 7 days at $37^{\circ} \mathrm{C}$ to allow the sealer to fully set.

\section{Push-Out Test}

Each sample was sectioned horizontally into $1 \mathrm{~mm}$ thick slices at each third (coronal, middle, and apical sections) of the root using a micro cut precision cutter (Metkon, Bursa, Turkey). Thirty samples 
were obtained from each group $(n=30)$. For the push-out test, the samples were tested in a universal test machine (Instron Corp, Norwood, MA, USA) using a stainless steel mill with a cross-head speed of $1 \mathrm{~mm} / \mathrm{min}$ ( $\mathrm{F}$ value in formula). The cylindrical stainless steel plunger tip (either $0.8,0.7$ or $0.5 \mathrm{~mm}$ in diameter) was selected for different root sections (coronal, middle, and apical). Push power was applied towards the apico-coronal until a bond failure occurred. The bond strength, measured in Newtons (N), was converted to megapascals (MPa) using the following formula:

$$
\text { pushoutbondstrength }(M P a)=\frac{F-\max (N)}{\text { adhesionsurfacearea }\left(\mathrm{mm}^{2}\right)}
$$

$\mathrm{F}=$ the force needed to dislodge the filling material

$\operatorname{Max}(\mathrm{N})=$ Dislodgement values
To determine the adhesion surface area, the following formula was used:

$$
\text { Adhesionsufracearea }\left(\mathrm{mm}^{2}\right)=\left(\frac{R_{1}+R_{2}}{2}\right) * \pi * h
$$

Where $\mathrm{R}_{1}$ is the coronal side radius, and $\mathrm{R}_{2}$ is the apical side radius; $\pi$ is the constant 3.14 ; and $h$ is the thickness of filled root samples. After the push-out test, the samples were examined with a stereomicroscope at $25 \mathrm{x}$ magnification to identify failure types. Failure types are classified according to Huffman et al. as follows: adhesive failure; failure between sealer and dentin surface; cohesive failure; failure within sealer; mixed failure; and failure in both dentin and sealer (Figure 2). A three-way analysis of variance (ANOVA) and a Tukey's post-hoc test were used, with significance set at $\mathrm{P}=0.05$ (SPSS software v20; IBM Corp., Armonk, NY, USA).

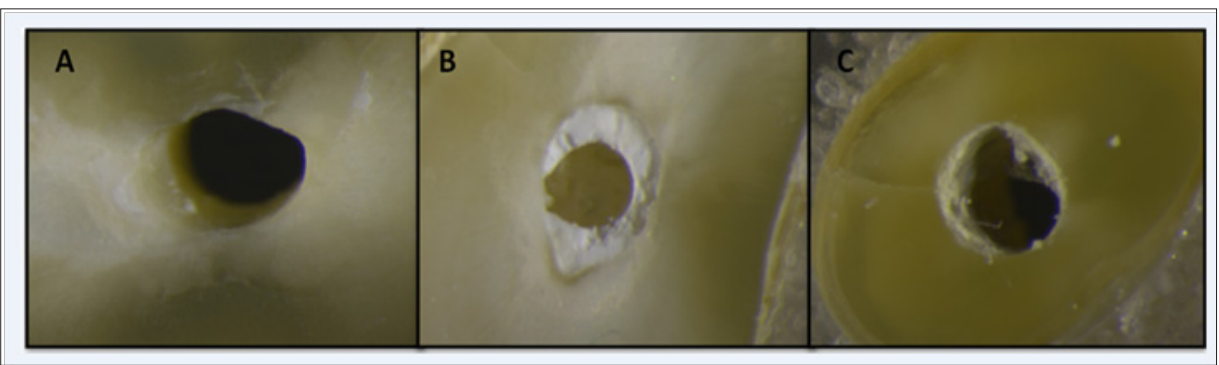

Figure 2: Specimen images of the failures modes. A) Adhesive failure, B) Cohesive failure, and C) Mixed failure.

\section{Results}

Push-out tests were not conducted for the samples obtained from the apical areas because of the small root canal diameters. Mean push-out bond strength and standard deviation values for the samples from the coronal and middle sections are given in Table 1. The main effects of the variables and their interactions are summarized in Table. The main effects of the regions were found to be statistically significant, while the bond strength was greater in the coronal section compared to the middle section $(\mathrm{P}<0.001)$. The bond strength values of the XP group were significantly higher than the values of the SAF and Reciproc groups $(\mathrm{P}<0.05)$. There were no significant differences between the SAF and Reciproc groups $(\mathrm{P}>0.05$. $)$ The interactions between instrumentation and the sealers were statistically significant $(\mathrm{P}<0.001)$, while there was no statistically significant interaction between the root third with sealers and the root third with instrumentation $(\mathrm{P}>0.05)$. The Table 1. Different letters indicate statistical significant difference ( sealer type did not have a statistically significant effect on bond strength $(\mathrm{P}>0.05)$. The distribution of failure types is shown in Figure 3. There is no statistically significant difference among the groups regarding the failure types.

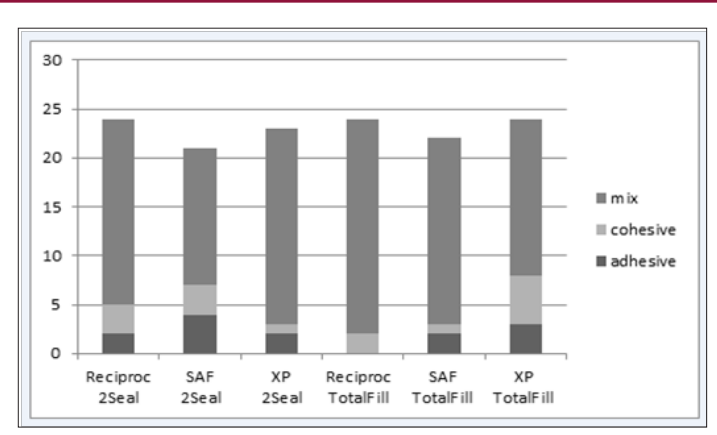

Figure 3: Failure modes for the experimental groups.

\begin{tabular}{|c|c|c|c|c|c|}
\hline Sealer & Root Third & Resiproc & Saf & Xp Endo & Pooled Avarage \\
\hline 2 Seal & Coronal & $1.85 \pm 1.04$ & $2.49 \pm 1.25$ & $1.9 \pm 0.49$ & $1.28 \pm 0.56$ \\
\hline & Middle & $1.23 \pm 0.46$ & $1.28 \pm 0.76$ & $1.67 \pm 0.91 \mathrm{~A}$ \\
\hline Total Fill BC & Coronal & $1.42 \pm 0.71$ & $1.19 \pm 0.62$ & $1.13 \pm 0.6$ & $1.48 \pm 0.89 \mathrm{~A}$ \\
\hline & Middle & $1.04 \pm 0.32$ & $0.98 \pm 0.64$ & $1.86 \pm 0.87 \mathrm{~b}$ & \\
\hline
\end{tabular}




\section{Discussion}

The difficulty involved in shaping and cleaning oval canals using a hand file [13], nickels titanium (NiTi) rotary instruments [14], Reciproc files [15], or a combination of these files [16] has been discussed in many studies. Rotary and reciprocal NiTi file systems result in a circular preparation because of their file shapes and the tendency of the file to stay in the center $[10,15,17,18]$. This results in the fins or recesses on the buccal and/or lingual surfaces remaining untouched in canals with greater buccolingual width [17]. The risk of having gaps between the dentin tissue and the canal filling as a result of insufficient filling of recesses during a root canal is high [19]. This is an important issue in the preparation of oval canals with significant anatomical differences [20]. The XP is a newly marketed file system about which there is little data. The file is prefabricated with a unique FKG alloy, the NiTi MaxWire (Martensite-Austenite Electropolish-Flex).

The XP file was developed to clean canals and prepare untouched areas within the root canal. It is suggested that XP be used as a finishing file system after preparation using a size 25 file. The creation and production of XP files are based on the shapememory characteristics of the NiTi alloy. The file can be returned to its original straight shape manually after it has cooled down (M-phase). The A-phase shape in the rotation mode allows the file to access and clean areas that are otherwise impossible to reach with standard instruments. In the present study, the aim is to compare the XP with the SAF system that is designed for differently structured canals, such as oval-shaped canals. Based on the results of the present study, the oval canals prepared with an XP file show a significantly higher bond strength value compared to the Reciproc and SAF systems. As a result, the null hypothesis was rejected. Higher bond strength values for the oval-shaped canals prepared with XP indicate that this newly designed NiTi file might improve the shaping and cleaning standards compared to the SAF system that is designed for complex canals.

The manufacturer claims that XP files have an expansion capacity that reaches 100 -fold compared to a standard instrument. The higher expansion capacity of the file might have allowed mechanical cleaning of the root canal surface in larger areas, which might have resulted in the higher bond strength values for the XP group. SAF is a NiTi file system that was developed after considering the disadvantages of the rotary instrumentation system $[5,12]$. When placed into the canal, SAF can adapt to canal walls in three dimensions for both longitudinal and cross sectional [21,22]. A micro CT study by Peters et al. [23] showed that the percentage of the prepared root canal area is higher using SAF compared to popular rotary file systems. Versiani et al. [21] stated that the preparations for canine teeth using four different rotary file systems and a Reciproc file for 4 min might result in the same shaping as the SAF system. In the present study, even though the bond strength of teeth prepared using the SAF system was higher than when using a Reciproc file, there was no significant difference between them.

The two dimension cutting angle and S-shaped geometry of the Reciproc file reduced the amount of debris in the root canal, [21] and so similar results in terms of bond strength might be found with the SAF system. Several studies have stated that dentin chips and soft tissue debris can be stacked in the fins or recesses in the buccal and lingual areas of oval canals after preparations using Reciproc and rotary instruments $[20,24,25]$. This debris cannot be removed, even with passive ultrasonic irrigation, and might prevent the complete filling of root canals [6,20]. Pawar et al. [10] have shown that the methods used for preparing oval-shaped canals might affect the bond strength of the root canal filling. In this study, a comparison of XP files to other file systems revealed the increased bond strength of root canal sealers. These results might be due to better contact with the canal walls compared to other files when considered in mechanical influence.

This study also revealed the tendency of decreased bond strength towards the corono-apical direction, as has been found in earlier studies $[10,26,27]$. This might be due to differences in the number and size of dentin tubules for different root sections. TotalFill BC improves the penetration of the sealer into anatomic irregularities and dentinal tubules [9]. The hydrophilic nature of the TotalFill BC sealer may have potentially resulted in more intimate contact with the canal walls than the hydrophobic and resin based AH plus sealer [9]. Because of this, two sealers with different characteristic were investigated the effect of bond strength to dentin in this present study. Some studies have indicated that bioceramic-based canal sealers have different bond strength values $[9,28,29]$. Some studies have shown that bioceramic-based sealers have a lower bond strength value compared to epoxy resin-based sealers [28,29], and others have shown they have higher bond strength values compared to epoxy resin-based sealers [9].

This difference might be due to the brand of canal sealer, different filling procedures, and examination period. The results of the present study reveal no statistically significant difference between the epoxy resin-based 2Seal and the bioceramic-based TotalFill BC canal sealer. Ersahan et al. [30] and Sağsen et al. [31] found that the bond strength of bioceramic-based iRoot SP sealer is similar to that of AH plus, which is an epoxy resin-based sealer. These findings are consistent with the results of the present study. Additional instrumentation applications of the XP for teeth with complex canal anatomy, such as oval-shaped canals, might increase the bond strength of different types of sealers. Further research is required to fully evaluate the canal shaping efficiency of the XP file system.

\section{References}

1. (2006) Quality guidelines for endodontic treatment: consensus report of the European Society of Endodontology. Int Endod J 39(12): 921-930.

2. Versiani MA, Pecora JD, De Sousa-Neto (2011) Flat-oval root canal preparation with self-adjusting file instrument: a micro-computed tomography study. J Endod 37(7): 1002-1007.

3. Peters OA, Schonenberger K, Laib A (2001) Effects of four Ni-Ti preparation techniques on root canal geometry assessed by micro computed tomography. Int Endod J 34(3): 221-230.

4. Paque F, Ganahl D, Peters OA (2009) Effects of root canal preparation on apical geometry assessed by micro-computed tomography. J Endod 35(7): 1056-1059. 
5. Metzger Z, Teperovich E, Zary R, Cohen R, Hof R (2010) the self-adjusting file (SAF). Part 1: respecting the root canal anatomy-a new concept of endodontic files and its implementation. J Endod 36(4): 679-690.

6. Metzger Z, Zary R, Cohen R, Teperovich E, Paqué F (2010) the quality of root canal preparation and root canal obturation in canals treated with rotary versus self-adjusting files: a three-dimensional micro-computed tomographic study. J Endod 36(9): 1569-1573.

7. Ehsani M, Zabihi E, Gharouee H (2012) A Comparison between Cytotoxicity Induced by Two Resin Based Sealers (2Seal and AH Plus) in Saos-2 and MG-63 Cell Lines. Int J Mol Cell Med 1(4): 197-202.

8. Zhang W, Li Z, Peng B (2010) Ex vivo cytotoxicity of a new calcium silicate-based canal filling material. Int Endod J 43(9): 769-774.

9. Nagas E, Uyanik MO, Eymirli A, Cehreli ZC, Vallittu PK, et al. (2012) Dentin moisture conditions affect the adhesion of root canal sealers. J Endod 38(2): 240-244.

10. Pawar AM, Pawar S, Kfir A, Pawar M, Kokate S (2016) Push-out bond strength of root fillings made with $\mathrm{C}$-Point and $\mathrm{BC}$ sealer versus guttapercha and $\mathrm{AH}$ Plus after the instrumentation of oval canals with the Self-Adjusting File versus WaveOne. Int Endod J 49(4): 374-381.

11. De-Deus G, Barino B, Zamolyi RQ, Souza E, Fonseca A, et al. (2010) Suboptimal debridement quality produced by the single-file F2 Pro Taper technique in oval-shaped canals. J Endod 36(11): 1897-900.

12. Metzger Z, Teperovich E, Cohen R, Zary R, Paqué F, et al. (2010) The self-adjusting file (SAF). Part 3: removal of debris and smear layer-A scanning electron microscope study. J Endod 36(4): 697-702.

13. Wu MK, Wesselink PR (2001) A primary observation on the preparation and obturation of oval canals. Int Endod J 34(2): 137-141.

14. Paque F, Balmer M, Attin T, Peters OA (2010) Preparation of ovalshaped root canals in mandibular molars using nickel-titanium rotary instruments: a micro-computed tomography study. J Endod 36(4): 703707.

15. Busquim S, Cunha RS, Freire L, Gavini G, Machado ME, et al. (2015) A micro-computed tomography evaluation of long-oval canal preparation using reciprocating or rotary systems. Int Endod J 48(10): 1001-1006.

16. Iqbal MK, Karabucak B, Brown M, Menegazzo E (2004) Effect of modified Hedstrom files on instrumentation area produced by ProFile instruments in oval canals. Oral Surg Oral Med Oral Pathol Oral Radiol Endod 98(4): 493-498.

17. Robinson JP, Lumley PJ, Cooper PR, Grover LM, Walmsley AD (2013) Reciprocating root canal technique induces greater debris accumulation than a continuous rotary technique as assessed by 3-dimensional microcomputed tomography. J Endod 39(8): 1067-1070.

18. Siqueira JF, Alves FR, Almeida BM, De Oliveira JC, Rôças IN (2010) Ability of chemo mechanical preparation with either rotary instruments or self-adjusting file to disinfect oval-shaped root canals. J Endod 36(11): 1860-1865.
19. Van der Sluis LW, Wu MK, Wesselink PR (2005) an evaluation of the quality of root fillings in mandibular incisors and maxillary and mandibular canines using different methodologies. J Dent 33(8): 683688.

20. De-Deus G, Souza EM, Barino B, Maia J, Zamolyi RQ, et al. (2011) the selfadjusting file optimizes debridement quality in oval-shaped root canals. J Endod 37(5): 701-705.

21. Versiani MA, Leoni GB, Steier L, De-Deus G, Tassani S, et al. (2013) Microcomputed tomography study of oval-shaped canals prepared with the self-adjusting file, Reciproc, Wave One, and ProTaper universal systems. J Endod 39(8): 1060-1066.

22. Paranjpe A, De Gregorio C, Gonzalez AM, Gomez A, Silva Herzog D, et al. (2012) Efficacy of the self-adjusting file system on cleaning and shaping oval canals: a microbiological and microscopic evaluation. J Endod 38(2): 226-231.

23. Peters OA, Boessler C, Paque F (2010) Root canal preparation with a novel nickel-titanium instrument evaluated with micro-computed tomography: canal surface preparation over time. J Endod 36(6): 10681072.

24. Paque F, Laib A, Gautschi H, Zehnder M (2009) Hard-tissue debris accumulation analysis by high-resolution computed tomography scans. J Endod 35(7): 1044-1047.

25. Paque F, Boessler C, Zehnder M (2011) Accumulated hard tissue debris levels in mesial roots of mandibular molars after sequential irrigation steps. Int Endod J 44(2): 148-153.

26. Neelakantan P, Varughese AA, Sharma S, Subbarao CV, Zehnder M, et al. (2012) Continuous chelation irrigation improves the adhesion of epoxy resin-based root canal sealer to root dentine. Int Endod J 45(12): 10971102.

27. Topcuoglu HS, Demirbuga S, Tuncay O, Arslan H, Kesim Bet al. (2014) the bond strength of endodontic sealers to root dentine exposed to different gutta-percha solvents. Int Endod J 47(12): 1100-1106.

28. Amin SA, Seyam RS, El-Samman MA (2012) the effect of prior calcium hydroxide intracanal placement on the bond strength of two calcium silicate-based and an epoxy resin-based endodontic sealer. J Endod 38(5): 696-699.

29. Oliveira DS, Cardoso ML, Queiroz TF, Silva EJ, Souza EM, et al. (2016) suboptimal push-out bond strengths of calcium silicate-based sealers. Int Endod J 49(8): 796-801.

30. Ersahan S, Aydin C (2010) Dislocation resistance of iRoot SP, a calcium silicate-based sealer, from radicular dentine. J Endod 36(12): 20002002.

31. Sagsen B, Ustun Y, Demirbuga S, Pala K (2011) Push-out bond strength of two new calcium silicate-based endodontic sealers to root canal dentine. Int Endod J 44(12): 1088-1091.

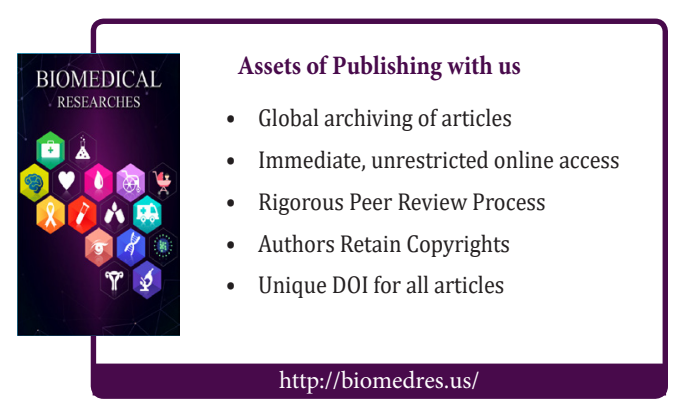

